\title{
Sleep, Sleepiness, and Fatigue on Board Faroese Fishing Vessels
}

\author{
Annbjørg Abrahamsen ${ }^{1,2}$, Pál Weihe $\mathbb{D}^{1,2}$, Fróði Debes $\mathbb{D}^{1}$, Wessel MA van Leeuwen $\mathbb{D}^{3}$ \\ 'Department of Occupational Medicine and Public Health, The Faroese Hospital System, Tórshavn, Faroe Islands; ${ }^{2}$ The University of Faroe Islands, \\ Faculty of Health Sciences, Tórshavn, Faroe Islands; ${ }^{3}$ Stockholm University, Department of Psychology, Stress Research Institute, Stockholm, Sweden \\ Correspondence: Wessel MA van Leeuwen, Stockholm University, Department of Psychology, Stress Research Institute, Stockholm, I069I, Sweden, \\ Tel +46 08-553 789 17, Email wessel.vleeuwen@su.se
}

Purpose: Faroese fishers have four times more accidents than workers on land. The aim was to understand fishers' fatigue better and how their work and sleep patterns influenced their sleepiness levels and cognitive performance.

Materials and Methods: A total of 157 Faroese fishers wore wrist-worn actigraphs at sea and one week on land and filled in sleep and sleepiness diaries during the trip. Furthermore, a 3-minute simple reaction time (SRT) test was completed at the beginning and end of the trip. The ship's movement and noise were also logged. The actiwatch results were analysed with mixed methods repeated measures. The sleepiness registrations and performance on the SRT-test were analysed with paired $t$-test. The ship movements (Pitch and roll) were divided into approximately three same-sized groups (lowest 1/3, medium 1/3, and highest 1/3) and compared against the Karolinska Sleepiness Scores (KSS ranging from 1-9) $\geq 7$ and physical tiredness (ranging from 1-9) scores $\geq 7$. Chi-square tests were used to determine the significance of these differences. Mean sleepiness scores at sea, and the proportion of sleepiness scores $\geq 7$ were calculated, as well as sleepiness scores as a function of the time of day.

Results: While at sea, fishers had more split sleep, slept less, and had lower sleep efficiency than onshore. Sleepiness was higher at the end of the trip, and cognitive decline was found. The number of major lapses was higher at the end of the trip, but with no significant difference between the median reaction times.

Conclusion: The crew on-board the freezer longliner, who worked $8-8$ shifts, slept the most, had the longest continuous sleep periods, the highest sleep efficiency, the lowest sleepiness levels, and the highest noise exposure during their time off.

Keywords: fisher, fishing, shift work, tired, actigraph

\section{Introduction}

Together with salmon harvesting, the fishing industry is the driving force of the Faroese economy, and fish and fish products consist of about $95 \%$ of the annual export goods. Consequently, the ability of the industry to attract employees is vital for the Faroe Islands. The waters of the North Atlantic surrounding the Islands can be rough due to storms and ocean currents. Sometimes, the rolling of the vessels makes it a challenging task for fishers to stand on their feet and stay safe. Besides these environmental challenges, and the nature of the job including high physical strain and repetitive movements, including much of manual material handling tasks, ${ }^{1}$ the fishing controls the workload and working hours, making it based on the magnitude of the catch rather than the clock, resulting in irregular and long working hours and limited and often fragmented sleep. McGuinness and colleagues stated that fishing generally is considered a dangerous occupation with a high risk of accidents. ${ }^{2}$ The last two decades have shown a decline in the accident rates in the Scandinavian countries and a $50 \%$ decrease in fatal accidents. ${ }^{3-5}$ The accident rates of Faroese fishers have stabilised since 2002, but fishers still have an accident rate that is four times higher than land workers. ${ }^{3}$ Fatigue has been identified as the largest single causal factor for accidents, accounting for $14 \%$ of the variance in cognitive failures. ${ }^{6}$ Across all types of maritime operations, seafarers' fatigue is one of the causal factors in $16 \%$ of critical vessel accidents. ${ }^{7}$

Sleepiness and fatigue are often used interchangeably, but although related, they are two different phenomena. Sleepiness is a condition that occurs in all individuals when lacking sleep and/or being awake for a prolonged period. 
It has a rapid onset but has a short-term effect on people's daily activities, and is easily remedied through adequate sleep. Fatigue has a more gradual onset and can be a long-term condition that may have adverse effects on people's mental and physical health, such as cognitive functions and emotions. ${ }^{8}$

Despite the growing awareness of the negative effects of both sleepiness and fatigue on safety and health in the transport sector, fatigue at sea has been less studied than in other modes of transport or safety-critical industries, ${ }^{9}$ and this is especially apparent with regard to fishing. ${ }^{10}$ Work at sea might result in sleepiness and fatigue due to several factors: (i) working hours often take place in what is referred to as the circadian nadir forcing sleep during less optimal hours of the day, ${ }^{11,12}$ (ii) environmental conditions such as harsh weather, rolling, vibrations and noise may result in difficulties obtaining rest and recuperation, ${ }^{13}$ and (iii) being away from home and family for prolonged periods may result in psychological stress, thereby causing sleep problems. ${ }^{14}$ Furthermore, work periods longer than eight hours, or series of shift work have been found to increase the risk of accidents and that this risk increases with time. ${ }^{11,15}$

Various shift systems are used in the maritime sector (eg, 6 on/ 6 off and 8 on/ 8 off). These shift systems all share that they permit less restitution by breaking up sleep into portions and requiring workers to sleep at unfavourable times of the day. ${ }^{12}$ Split-sleep is not in line with the inner biological clock ${ }^{16}$ and has been found to be associated with severe sleepiness to such a degree that it strongly increases the risk of accidents. ${ }^{17,18}$

In addition to ship movement, noise also has the potential to increase fatigue. ${ }^{19}$ Studies of the relationship between nocturnal noise exposure and health find adverse health effects in populations exposed to noise levels at night between 40-55 dB(A), with evidence for increased risks for cardiovascular diseases when exceeding $55 \mathrm{~dB}(\mathrm{~A})$ (Night noise guidelines for Europe, WHO 2009). Disturbed sleep is one of the most frequently expressed complaints by noise-exposed populations, which is also confirmed by a questionnaire survey among Norwegian seafarers. ${ }^{20}$ Sleep disturbances manifest through "arousal responses, sleep stage changes, awakenings, body movements, increased total wake time, and autonomic responses" (WHO, Regional Office for Europe, 2011). When awake, it is manifested through daytime sleepiness and general deterioration of daytime functioning levels (WHO, Regional Office for Europe, 2011).

The current study included four of the vessel types that constitute the Faroese fishing fleet. Netting vessels are characterised by crew having long (14-18 hours) working days and short trip lengths (about 4 days). Trawlers have their working hours entirely controlled by the catch and a trip length spans about 5 days. Longliners have more clearly defined shift systems, with 6 hours on /6 hours off being the most dominant, and with trip lengths of about 14 days. Finally, longliners with freezers on board are comparable to the ordinary longliners but have considerably longer trips, that can last up to over 40 days. More detailed comparisons between the different vessel types and the work on board are shown in Table 1.

The current study aims to investigate sleep, sleepiness, and fatigue among fishers on four different Faroese fishing vessel types. Sleep, sleepiness, and fatigue at sea will be compared to sleep at home.

We hypothesise that (1) the sleep of fishers is worse at sea than on land, both regarding length and efficiency, (2) differences in sleep duration between fishers in the four ship groups exist while at sea and, (3) sleepiness levels during working hours will be inversely correlated with sleep quality and quantity. Finally, (4) we expect environmental factors such as ship movement and noise to differ between ship types, and thereby, contribute to the differences in sleep and sleepiness levels.

\section{Materials and Methods}

Study Population

Out of about 1750 full-time Faroese fishers, 176 were invited to participate in the study. Of these, 157 agreed to participate (89\%); 156 men and 1 woman with a mean age of $42 \pm 16$ years. The fishers rated their general health as good, with $92 \%$ rating their health as either good, very good or excellent. Their average BMI was 26.7 (SD = 5.3). Out of the 130 fishers who reported their blood pressure, $26(20 \%)$ received medicine for hypertension, and six for diabetes type 2. The fishers were divided over the four vessel groups as follows: netting vessels, $\mathrm{n}=34$; longliners without freezing facilities, $\mathrm{n}=90$; trawlers, $\mathrm{n}=19$; longliners with freezing facilities, $\mathrm{n}=14$. Participation was voluntary, and the data collection was pseudonymised. All participants gave their written informed consent before taking part in the study. The study has received approval by the Faroese Committee on Biomedical Research Ethics and the Faroese Data Inspection 
Table I Characteristics (Mean \pm Standard Deviation) of the Participating Vessel Groups

\begin{tabular}{|c|c|c|c|c|c|}
\hline & $\begin{array}{l}\text { Long Liner } \\
\text { Fresh Fish }\end{array}$ & $\begin{array}{l}\text { Long Liner } \\
\text { Freezer }\end{array}$ & $\begin{array}{l}\text { Netting } \\
\text { Vessel }\end{array}$ & Trawler Boat & Overall \\
\hline \#of participants & 90 & 14 & 34 & 19 & 157 \\
\hline Work experience as a fisher (years) & $25.1 \pm 14.1$ & $17.7 \pm 18.2$ & $17.6 \pm 16.2$ & $27.8 \pm 15.2$ & $19.5 \pm 16.3$ \\
\hline Age (years) & $42.3 \pm 16.7$ & $36.3 \pm 15.4$ & $41.8 \pm 15.4$ & $46.33 \pm 15.2$ & $42.1 \pm 16.1$ \\
\hline BMI & $26.3 \pm 5.6$ & $27.9 \pm 6.1$ & $25.7 \pm 4.8$ & $29.0 \pm 4.4$ & $26.7 \pm 5.3$ \\
\hline $\begin{array}{l}\text { Diurnal preference ( } 1 \text {, extreme morning to } 5 \text {, } \\
\text { extreme vening) }\end{array}$ & $3.3 \pm 1.3$ & $3.3 \pm 1.3$ & $3.1 \pm 1.4$ & $2.4 \pm 1.3$ & $3.2 \pm 1.4$ \\
\hline Self-reported sleep need $(\mathrm{min})$ & $445.7 \pm 82.5$ & $436.2 \pm 84.5$ & $462.0 \pm 76.2$ & $476.1 \pm 153.3$ & $452.9 \pm 93.6$ \\
\hline KSQ Sleep quality index & $4.2 \pm 1.1$ & $4.1 \pm 1.4$ & $4.43 \pm 0.8$ & $4.6 \pm 0.9$ & $4.3 \pm 1.1$ \\
\hline KSQ non-restorative sleep index & $4.4 \pm 1.1$ & $4.4 \pm 1.9$ & $4.2 \pm 0.9$ & $4.5 \pm 0.8$ & $4.4 \pm 1.0$ \\
\hline KSQ Sleep apnea index & $5.1 \pm 1.1$ & $5.0 \pm 1.3$ & \pm 3.5 & $5.1 \pm 0.62$ & $5.0 \pm 1.1$ \\
\hline KSQ Sleepiness \& Fatigue index & $4.6 \pm 0.8$ & $4.9 \pm 0.7$ & $4.5 \pm 1.3$ & $4.5 \pm 0.8$ & $4.6 \pm 0.8$ \\
\hline MFI General Fatigue & $12.1 \pm 2.4$ & $13.0 \pm 2.2$ & $11.8 \pm 2.3$ & $11.2 \pm 2.1$ & $12 \pm 2.3$ \\
\hline MFI Physical fatigue & $9.9 \pm 2.0$ & $9.4 \pm 2.7$ & $9.1 \pm 1.9$ & $8.7 \pm 2.1$ & $9.5 \pm 2.1$ \\
\hline MFI Mental fatigue & $9.4 \pm 2.1$ & $8.6 \pm 2.1$ & $9.4 \pm 1.9$ & $8.8 \pm 2.6$ & $9.2 \pm 2.1$ \\
\hline MFI Reduced activity & $9.4 \pm 3.2$ & $8.2 \pm 2.7$ & $8.9 \pm 3.3$ & $10.4 \pm 3.1$ & $9.2 \pm 3.1$ \\
\hline MFI Reduced motivation & $8.1 \pm 2.7$ & $6.6 \pm 2.3$ & $7.6 \pm 2.5$ & $6.8 \pm 2.1$ & $7.7 \pm 2.6$ \\
\hline GHQ overall & $2.7 \pm 0.4$ & $2.7 \pm 0.4$ & $2.7 \pm 0.4$ & $2.6 \pm 0.7$ & $2.7 \pm 0.4$ \\
\hline \# of trips & 8 & 1 & 4 & 5 & 18 \\
\hline \# of ships & 9 & 4 & 5 & 7 & 25 \\
\hline Average trip length (days) & $13.9 \pm 3.0$ & 39 & $3.4 \pm 2.3$ & $5.2 \pm 2.9$ & $10.7 \pm 8.8$ \\
\hline Days in each ship group & 111 & 39 & 17 & 26 & 193 \\
\hline Noise exposure during work (dB) & $87.9 \pm 9.4$ & $82.1 \pm 7.8$ & $83.4 \pm 6.6$ & $85.1 \pm 8.8$ & $86 \pm 8.9$ \\
\hline Noise exposure during time-off $(\mathrm{dB})$ & $66.5 \pm 5.3$ & $74.2 \pm 6.4$ & $73.8 \pm 5.3$ & $69.4 \pm 6.6$ & $68.6 \pm 6.1$ \\
\hline Noise exposure for $24 \mathrm{~h}$ day $(\mathrm{dB})$ & $84.8 \pm 8.6$ & $82.5 \pm 8.2$ & $83 \pm 6.4$ & $82.6 \pm 8.1$ & $83.8 \pm 8.1$ \\
\hline Noise diff. between work and time-off $(\mathrm{dB})$ & $21.4 \pm 11.5$ & $7.9 \pm 10.4$ & $9.6 \pm 7.7$ & $15.7 \pm 11.7$ & $17.4 \pm 11.8$ \\
\hline Mean Roll (degrees) & 3.9 & 3.9 & 3.3 & 3.3 & 3.8 \\
\hline Max Roll (degrees) & 59.10 & 33.6 & 39.8 & 59.1 & 59.1 \\
\hline Mean Pitch (degrees) & 2.6 & 1.8 & 4.2 & 4.1 & 3.1 \\
\hline Max Pitch (degrees) & 43.6 & 29.8 & 39.0 & 56.2 & 56.2 \\
\hline
\end{tabular}

Abbreviations: dB, decibels; BMI, body mass index; KSQ, Karolinska Sleep Questionnaire; MFI, Multidimensional Fatigue Inventory; GHQ, General Health Questionnaire.

Agency J. nr. 16/00230-13, and was conducted in accordance with the declaration of Helsinki. Table 1 shows the background characteristics of the participants.

\section{Data Collection}

Data collection took place between May 2017 and July 2018 and was part of a larger project investigating the life and well-being of Faroese fishers. The first author was on board all the vessels, monitoring and collecting data. A paper and electronic questionnaire were used to collect demographic data, data about work and work history, and various psychometric questionnaires. Since the questionnaire was long, those who had not finished filling in the electronic questionnaire were encouraged by the first author to do so, while at sea. If fishers expressed problems with reading or writing, the author offered to read out the questions to the fishers.

\section{Procedure}

As soon as the fishers entered the ship, the data collection started. The whole process, including the training sessions, took about 3-4 hours, while sleep diaries, registrations of sleepiness and physical tiredness (all more thoroughly explained below), continued throughout the whole trip. After the last work shift, prior to resting, all the tests and procedures as explained above, which were conducted at the beginning of the trip, were repeated to see if there were any differences in the fishers' mental functions as a result of fatigue. 


\section{Measurements}

\section{Sleep Data from Actigraphs}

Wrist-worn actigraphs, the ActiGraph GT9X link with an epoch length of 60 seconds and a sampling rate of $30 \mathrm{~Hz}$ (ActiGraph Inc., Florida, USA) were used as objective measures of sleep and activity. The Actigraphs were worn continuously during the whole trip, and a total of 4133 sleep periods were collected. Regarding the data handling, the Cole-Kripke algorithm was used to detect sleep periods. In cases where the sleep was not detected with the algorithm, sleep periods were manually corrected according to the sleep diaries. When inserting such sleep periods manually, sleep onset was determined by a consistent number of epochs (five in a row), below activity level 20. Total sleep periods of five minutes or lower $(n=29)$ were deleted, as well as sleep periods with higher sleep efficiency than $98.5 \%(n=125)$ or lower than $5 \%(\mathrm{n}=8)$. There was no lower limit for wearing the watch for inclusion in the dataset, since this was not needed. The vast majority of fishers wore the watch all the time. It happened quite a few times, that the watch strap broke, but this usually only caused less than 1 hour of no-wear, as extra straps were ready for replacement. From the data collected with the actigraphs, the total number of sleep periods, the mean sleep duration per day, the time difference between minutes in bed vs minutes asleep, and the mean number of sleep periods per day were calculated. Data on wake after sleep onset (WASO), sleep fragmentation, average awakening length, number of awakenings, sleep efficiency, and movement during sleep were collected. Comparisons between sleep at sea and on land were made, with fishers also wearing the actigraphs for approximately one week on land. See Figure 1 for examples of actigraphy recordings of fishers from the four vessel groups at sea and on land.

\section{Sleep Diaries, Sleepiness and Physical Fatigue Recordings}

Sleep diaries were used to register subjective sleep data, and the Karolinska Sleepiness Scale (KSS (Torbjörn Åkerstedt \& Gillberg, 1990)), ranging from 1 (very alert) to 9 (very sleepy), was used to register sleepiness during the trip. A similar scale for physical fatigue, also ranging from 1 to 9 , with 1 (very rested) and 9 (extremely physically tired) was also represented in the diary after the first 3 trips, as a result of repeated requests from the fishers who kept saying that they did not feel sleepy, but physically tired, and that they did not feel that the sleepiness scale covered the physical dimension. The choice was given to register on a paper diary, or electronically in an app made for this purpose. However, as the internet on most vessels usually was not available on deck, and only in certain areas of the ship, mainly the paper version was used. Fishers were instructed to register their sleepiness in a KSS diary at least every other hour while at work and to register their sleep periods by writing down what time they went to bed (lights out) and woke up. Reminders were occasionally given by the on-board researcher, when passing them on the deck and/or while in the mess-room, around the meals. Regarding the sleep diaries reminders were usually given around the shift changes, as well as occasionally at other times. From the KSS, mean sleepiness scores at sea, and the proportion of sleepiness scores $\geq 7$ were calculated, as well as sleepiness scores as a function of the time of day. Comparisons were made based on the differences between the ship groups.

\section{Cognitive Testing}

The cognitive tests were carried out with COMPASS 5.0 software (a computerised mental performance assessment system developed by Northumbria University in Newcastle, UK). The software was installed on eight computers using a wired mouse, and was used to assess a variety of areas within mental functioning. A simple reaction time test (SRT), which has been shown to be a reliable and objective way of measuring sleepiness was used. The results from the other five tests which were used to test the fishers' cognitive functions will be discussed in a separate article about the effect of fatigue on cognition. From COMPASS, the median from 50 stimuli on the Simple Reaction Time test (SRT) was obtained, as well as a count of the slowest reaction times (rt); minor lapses (rt $>500 \mathrm{~ms}$ ) and major lapses (rt $>1000 \mathrm{~ms}$ ) were counted. Lapses refer to the failure to respond promptly to an expected stimulus (Doran, Van Dongen and Dinges, 2001). Before completing the cognitive tests on the computer, the fishers provided details about their activities during the last 24 hours, including questions about sleep, food and alcohol intake, number of cigarettes, and date and time of testing. They underwent four training sessions to flatten a possible learning curve. After a break, most often the next morning before starting their first shift or during the first shift, the 


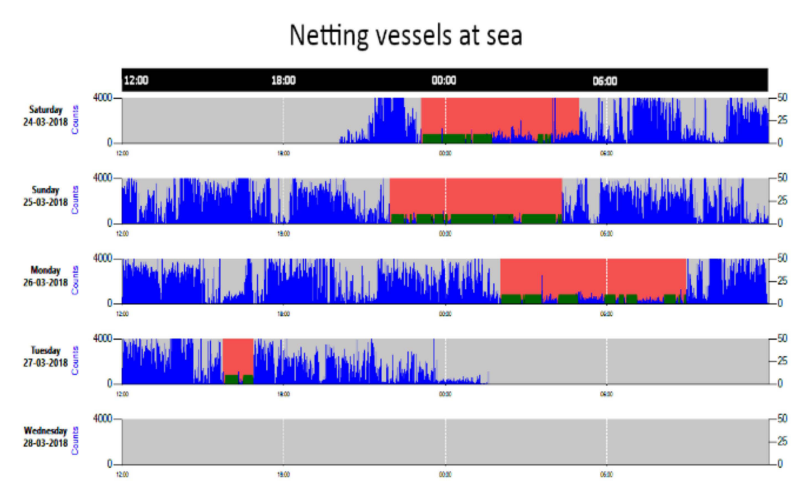

Netting vessels at home

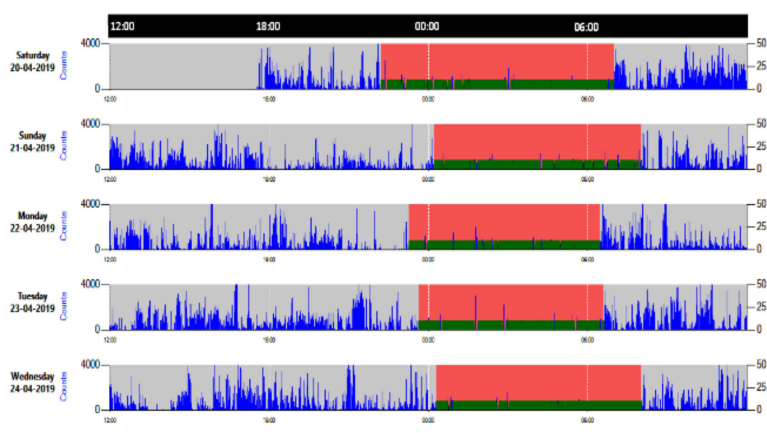

Longliner at sea

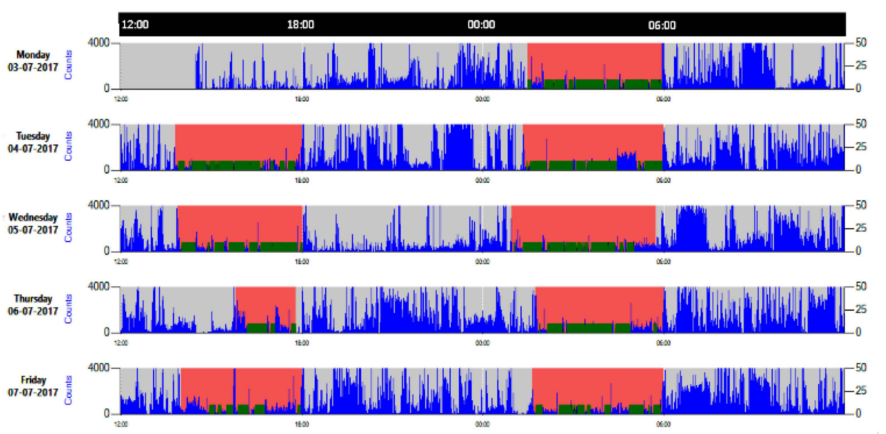

Longliner at home
Trawler at sea

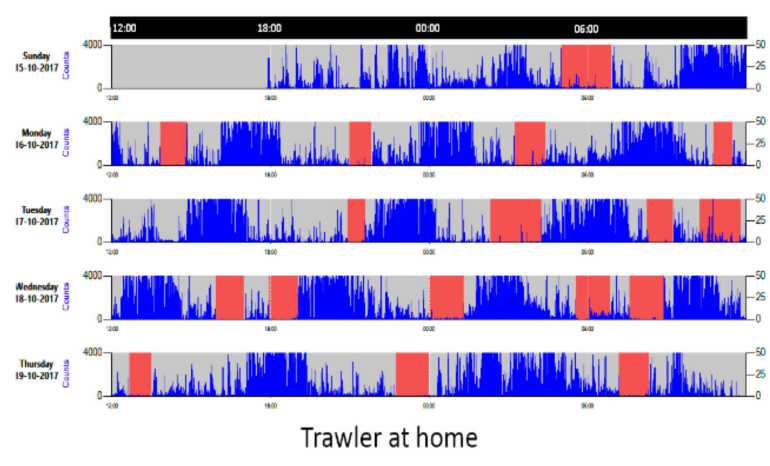

Longliner freezer at sea

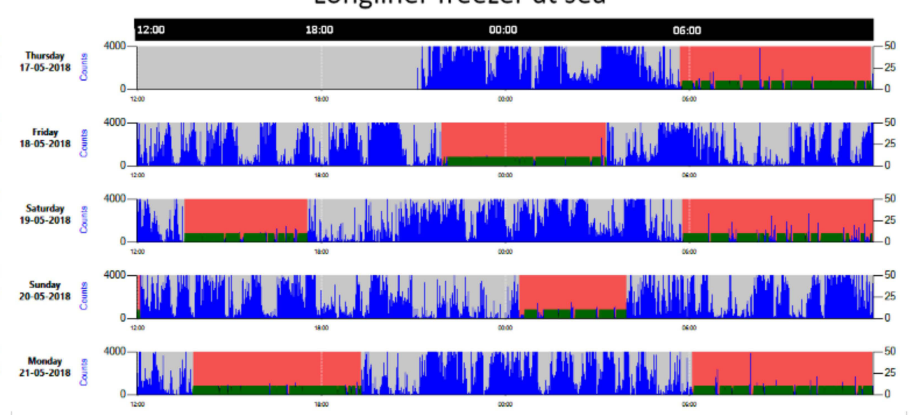

Longliner freezer at home

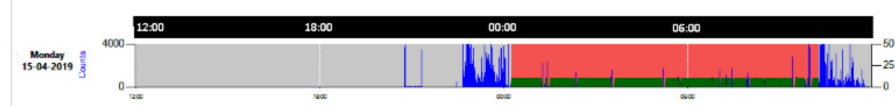

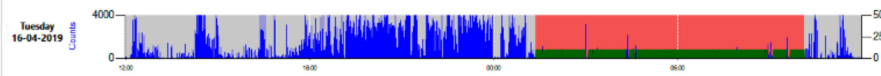

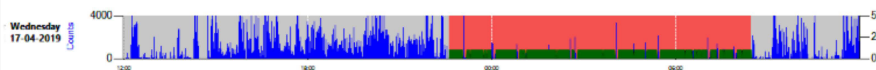

1.

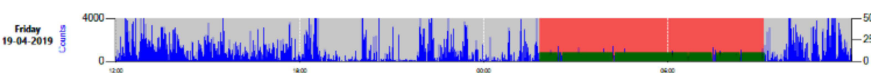

Figure I Actigraphy recordings of one representative fisher for each vessel group, during five days at sea, or the length of the trip, if shorter than five days, and five days at home. The recordings show the fishers rest/activity cycles and was used to study sleep/wake patterns. The pink and green bars indicate the periods when he first fell asleep and woke up, as determined by the algorithm. The blue colour indicates activity in awakened state. The actigraph was worn on the non-dominant wrist and continually recorded movement. 
fishers provided details about their last 24 hours again and rated their sleepiness (KSS) to get a measure of their sleepiness level before they completed the cognitive tests in COMPASS. The SRT test took about three minutes to complete.

\section{Ship Movement Measurements}

Ship movements were logged for the whole trip using a gyroscope $(30 \times 30 \times 20 \mathrm{~cm})$ with two inbuilt sonar sensors (Taeko scl-30a1, Foruna Industries, Esbjerg) positioned in the wheelhouses near the centre of the ship. The gyroscope was connected to a laptop and registered the ship's movement along two planes: rolls from side to side and the pitch from fore to aft. Computer software delivered by Picolog logged the data for rolling and pitching, Pico Technology (PicoLog data acquisition software, Leeds, UK, Accessed March, 2013).

\section{Noise Measurements $(\mathrm{dB}(\mathrm{A}))$}

The noise was logged, usually measuring during a whole shift in each working station and in the resting areas, using Casella SEL-633 Environmental \& Occupational Noise meter, which provides Sound Pressure Levels (SPL), integrating and octave band noise measurements compliant with international standards. (Casella, Bedford, UK). From knowledge about the fishers' working schedule and the decibel level measured in each working and resting station, three individual noise exposure profiles were calculated for noise exposure per 24-hour period, for the working hours per day, and the resting period respectively.

\section{Statistical Analysis}

The Actigraphy data was processed and analysed using ActiLife 6.13.4 Data Analysis Software. All data was analysed using SPSS software, version 25 (IBM Corp., Armonk, NY, USA). Descriptive statistics are presented as mean and standard deviation for continuous variables and as a percentage for categorical for the demographic data, and scores on sleep and sleepiness scales. Chi-square statistics were used to compare the frequency of severe sleepiness $($ KSS $>7)$ between the four vessel groups. Mixed-model linear regression analysis was used on the actigraphy data. The simple reaction time tests (SRT) as well as the KSS scores reported in conjunction with them were analysed using paired t-tests. Pitch and roll movements of the vessels were divided into approximately three same-sized groups (lowest 1/3, medium 1/ 3 , and highest 1/3), and compared against KSS and physical tiredness. Chi-square tests were used to determine the significance of these differences. Correlation analyses were used to test for associations between ship movement and sleep efficiency, between noise and sleep efficiency, and between noise and KSS.

\section{Results}

\section{Sleep and Sleepiness}

Severe Sleepiness and Simple Reaction Time

From the KSS ratings obtained at sea, the fishers' mean sleepiness score over the day was calculated and presented in Figure 2. The figure shows a clear trend, showing that fishers report higher sleepiness scores during the night than during the day, regardless of shift type.

Furthermore, the frequency analysis of severe sleepiness (KSS $\geq 7$ ) over 24 hours demonstrates a clear pattern, with fishers showing the highest prevalence of severe sleepiness during late evening/night and early morning (Figure 2). Severe sleepiness was more prevalent on netting vessels $(25.5 \%)$ compared to trawlers $\left(18.5 \% ; \chi^{2}(1)=7.2 ; \mathrm{p}=0.0073\right)$, longliners $\left(16.0 \% ; \chi^{2}(1)=32.3 ; \mathrm{p}<0.0001\right)$, and freezer longliners $\left(12.8 \% ; \chi^{2}(1)=55.8 ; \mathrm{p}<0.0001\right)$. The differences between trawlers $(18.5 \%)$ and freezer longliners $\left(12.8 \% ; \chi^{2}(1)=9.6 ; p=0.002\right)$, and between freezer longliners $(12.8 \%)$ and longliners $\left(16.0 \% ; \chi^{2}(1)=10.3 ; p=0.0013\right)$ were also statistically significant. Sleepiness distribution curves by vessel type are shown in Figure 3, illustrating that the sleepiness on-board the longliners (with and without freezing facilities) is less severe than on board netting vessels.

The median of the simple reaction time tests (SRT) and KSS results conducted at the beginning and the end of the trip are displayed by vessel type in Table 2. It can be observed that KSS was higher at the end of the trips compared to the beginning, whereas SRT remained at a similar level. There was no significant change in the number of minor lapses (rt $>$ 500ms). However, for longliners and trawlers, a significant change was observed in the number of major lapses ( $\mathrm{rt}>$ 


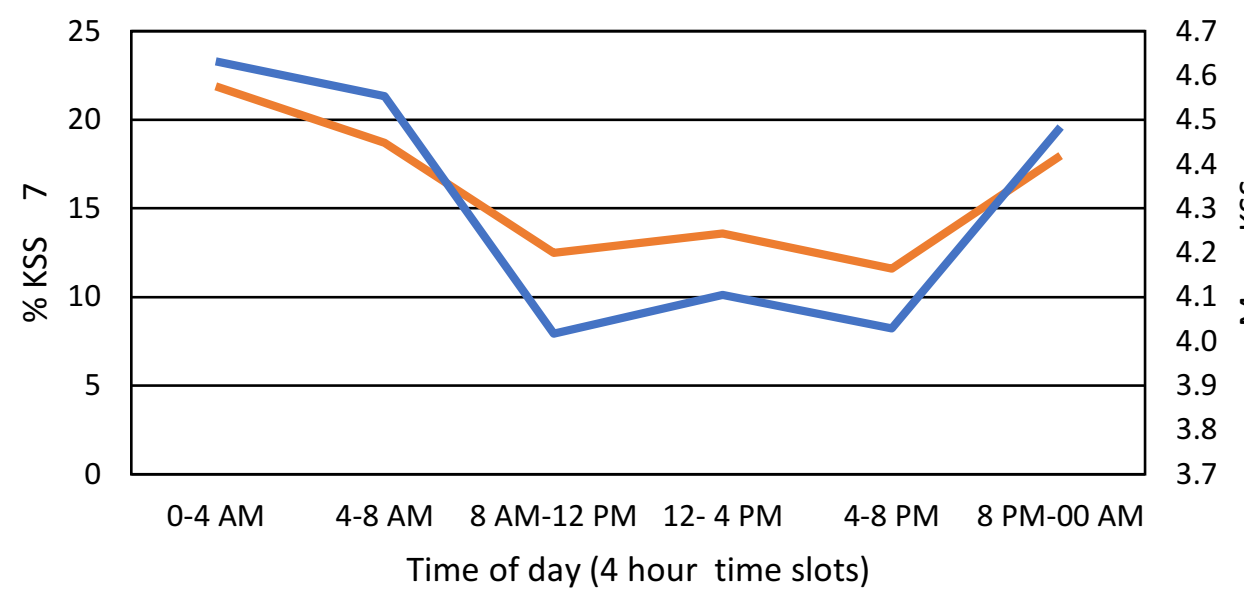

\% KSS 7 Mean KSS

Figure 2 Mean for all fishers and occurrence of severe sleepiness (\% KKS $\geq 7)$ as a function of time of day

$1000 \mathrm{~ms})$. For the longliners, there were more rt $>1000 \mathrm{~ms}, 0.62(1.07)$ vs $1.23(2.56)$ with $\mathrm{t}(86)=-2.323, \mathrm{p}=0.023$, and for the trawler crew, significantly more major lapses, $\mathrm{rt}>1000 \mathrm{~ms}$ were also observed in the end of the trip $0.56(0.71)$ versus 1.33 (1.41), with $\mathrm{t}(17)=-2.30, \mathrm{p}=0.035$. When running the analysis of the median reaction time, and lapses $>$ $500 \mathrm{~ms},>1000 \mathrm{~ms}$, respectively on all fishermen as a whole, significant differences were found on the number of RT $>$ $1000 \mathrm{~ms}(\mathrm{t}(147)=-2.659, \mathrm{p}=0.009)$ between the measures at the beginning of the trip and the end.

\section{Actigraphy}

Sleep diaries were used as subjective sleep recordings and to solve any potential unclarities in the actigraphy data concerning sleep on- and offset. The data from the actigraphs were used to calculate the number of sleeps per day, time in bed per day, sleep duration per day, sleep duration per sleep, the difference between minutes in bed vs minutes asleep, sleep efficiency (\%), sleep fragmentation index, fragmentation index, movement index, average awakening length, number of awakenings, wake after sleep onset (WASO) and sleep latency. Considerable differences in sleep parameters were observed at sea versus on land; the number of sleeps per day was higher at sea $(1.8$ vs $1.1 ; \mathrm{p}<0.001)$ while the total

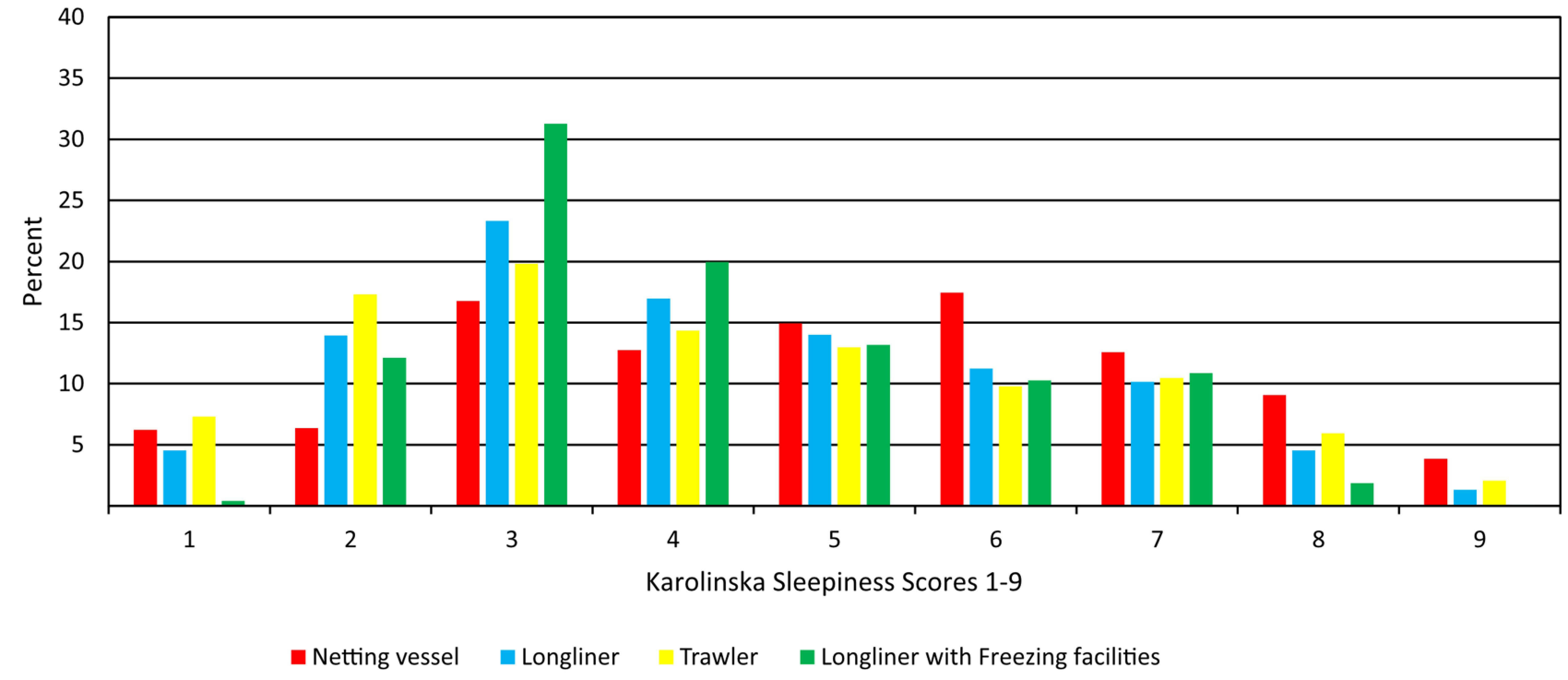

Figure 3 Sleepiness on board all ship groups. 
Table 2 Differences Between the Median SRT and KSS Scores at the Beginning and End of the Trips with Paired t-test Results

\begin{tabular}{|c|c|c|c|c|c|c|c|c|}
\hline \multirow{3}{*}{$\begin{array}{l}\text { Vessel Type } \\
\text { Netting vessel SRT }\end{array}$} & \multirow{3}{*}{$\begin{array}{l}\mathbf{N} \\
30\end{array}$} & \multicolumn{3}{|l|}{ Start } & \multicolumn{3}{|l|}{ End } & \multirow{3}{*}{$\begin{array}{l}\text { Sig. } \\
\text { ns }\end{array}$} \\
\hline & & \multirow{2}{*}{$\begin{array}{r}\text { Mean } \\
339.4\end{array}$} & \multicolumn{2}{|c|}{ SD } & \multirow{2}{*}{$\begin{array}{r}\text { Mean } \\
335.8\end{array}$} & \multicolumn{2}{|c|}{ SD } & \\
\hline & & & \pm & 75.9 & & \pm & 71.3 & \\
\hline Netting vessel KSS & 13 & 2.9 & \pm & 1.5 & 5.7 & \pm & 1.4 & $p<0.001$ \\
\hline Longliner fresh SRT & 87 & 333.4 & \pm & 67.2 & 333.8 & \pm & 90.1 & ns \\
\hline Longliner fresh KSS & 42 & 3.8 & \pm & 1.8 & 5.8 & \pm & 1.9 & $p<0.001$ \\
\hline Longliner freezer SRT & 13 & 311.3 & \pm & 61.7 & 330.0 & \pm & 61.7 & ns \\
\hline Longliner freezer KSS & 12 & 2.9 & \pm & 0.1 & 5.8 & \pm & 1.6 & $p<0.001$ \\
\hline Trawler SRT & 18 & 346.1 & \pm & 69.3 & 329.7 & \pm & 54.9 & ns \\
\hline Trawler KSS & 14 & 3.9 & \pm & 1.8 & 5.7 & \pm & 2.2 & ns \\
\hline All vessels SRT & 148 & 333.0 & \pm & 67.9 & 334.5 & \pm & 82.1 & ns \\
\hline All vessels KSS & 81 & 3.5 & \pm & 1.7 & 5.8 & \pm & 1.8 & $p<0.001$ \\
\hline
\end{tabular}

Abbreviation: ns, non significant.

duration of sleep per day was lower (272 vs 419 minutes; $p<0.001$ ). Consequently, individual sleep episodes were much shorter at sea than on land (162 vs 377 minutes; $\mathrm{p}<0.001)$. Furthermore, the time spent in bed without being asleep was longer at sea (146 minutes) than on land (72 minutes) $(\mathrm{p}<0.001)$. (Table 3$)$.

\section{The Relation Between the Ship's Movement and Severe Sleepiness and Physical Tiredness}

The three KSS and physical tiredness levels were compared between the different pitching (ship movements from fore to aft) and rolling (ship movements from side to side) grouped (i.e. low, middle, and high; Table 4). A U-shaped trend shows that the middle score of ship movement is associated with the lowest prevalence of both severe sleepiness and physical tiredness. The qui-square tests revealed significant differences between KSS and pitch, low vs high $\mathrm{p}<0.001$; KSS and pitch, middle vs high $\mathrm{p}<0.0001$; KSS and roll, low vs middle $\mathrm{p}<0.0001$; KSS and roll, middle vs high $\mathrm{p}<0.5$; KSS and roll, low vs high $\mathrm{p}>0.01$, Physical tiredness and pitch, low and high $\mathrm{p}<0.0001$; physical tiredness vs pitch, middle and high $\mathrm{p}<0.0001$; physical tiredness and roll, low vs middle $\mathrm{p}>0.0001$; physical tiredness, low vs high $\mathrm{p}<0.0001$.

\section{Ship Movement Correlations with Sleep Efficiency}

In addition to having ship movement influencing the fishers in their hours awake, mean rolling and pitching per day are negatively correlated to the fishers' sleep efficiency $r(2753)=-.27$, and $r(2753)=-.07$, both at the level of $p<0.0001$.

\section{Noise Exposure Correlations with Sleep, Sleepiness and Physical Tiredness}

The amount of noise exposure correlated negatively with sleep efficiency during working hours $r(2992)=-.099, p<$ 0.0001 , and positively with sleep efficiency in the resting hours $r(2992)=.98, p<0.0001$.

Sleepiness (KSS) correlated positively with noise exposure $\mathrm{dB}(\mathrm{A})$ during the 24 hours of the day $r(1380)=.11, \mathrm{p}<$ 0.0001 , and noise exposure $\mathrm{dB}(\mathrm{A})$ during work $r(1380)=.06, p<0.05$, and negatively to noise exposure during the resting hours $r(1380)=-.08, p<0.01$. Furthermore, physical tiredness correlated positively to $\mathrm{dB}(\mathrm{A})$ per 24-hour day and to $\mathrm{dB}(\mathrm{A})$ exposure during working hours $r(1165)=.09, p<0.01$, and $\mathrm{r}(1165)=.14, p<0.0001$, respectively. 
Table 3 Sleep and Sleepiness of Faroese Fishermen in Four Vessel Groups at Sea and on Land Measures Obtained from Actigraphy

\begin{tabular}{|c|c|c|c|c|c|c|c|c|}
\hline \multirow[t]{2}{*}{ Measures } & \multirow[b]{2}{*}{$\mathbf{N}$} & \multicolumn{2}{|c|}{ Sea } & \multirow[b]{2}{*}{$\mathbf{N}$} & \multicolumn{2}{|c|}{ Land } & \multirow[b]{2}{*}{$\mathbf{F}$} & \multirow[b]{2}{*}{ p - value } \\
\hline & & Mean & $\pm S D$ & & Mean & $\pm S D$ & & \\
\hline \multicolumn{9}{|c|}{ Number of sleeps/24 hour } \\
\hline Netting vessels & 31 & 1.3 & 0.4 & 30 & 1.2 & 0.3 & 1.62 & 0.110 \\
\hline Longliners & 89 & 1.9 & 0.3 & 66 & I.I & 0.2 & 248.36 & $\leq 0.001$ \\
\hline Trawlers & 19 & 2.1 & 0.7 & 19 & I.I & 0.3 & 35.53 & $\leq 0.001$ \\
\hline $\begin{array}{l}\text { Longliner with freezing } \\
\text { facility }\end{array}$ & 14 & 1.6 & 0.4 & 13 & 1.1 & 0.1 & 15.87 & $\leq 0.001$ \\
\hline All ships & 153 & 1.8 & 0.5 & 128 & I.I & 0.3 & 183.46 & $\leq 0.001$ \\
\hline \multicolumn{9}{|c|}{ Sleep duration per day/min } \\
\hline Netting vessels & 31 & 250.3 & 94.9 & 30 & 437.1 & 101.8 & 55.00 & $\leq 0.001$ \\
\hline Longliners & 89 & 278.8 & 76.3 & 66 & 409.3 & 193.2 & 33.64 & $\leq 0.001$ \\
\hline Trawlers & 19 & 233.4 & 80.2 & 19 & 414.9 & 87.7 & 44.28 & $\leq 0.001$ \\
\hline $\begin{array}{l}\text { Longliner with freezing } \\
\text { facility }\end{array}$ & 14 & 332.5 & 40.8 & 13 & 430.1 & 80.6 & 16.10 & $\leq 0.001$ \\
\hline All ships & 153 & 272.3 & 81.8 & 128 & 418.8 & 152.7 & 104.85 & $\leq 0.001$ \\
\hline \multicolumn{9}{|l|}{ Sleep duration per sleep } \\
\hline Netting vessels & 31 & 198.9 & 63.7 & 30 & 385.6 & 72.9 & 113.57 & $\leq 0.001$ \\
\hline Longliners & 89 & 149.3 & 48.1 & 66 & 369.4 & 151.2 & 166.28 & $\leq 0.001$ \\
\hline Trawlers & 19 & 117.7 & 50.0 & 19 & 382.9 & 66.3 & 193.56 & $\leq 0.001$ \\
\hline $\begin{array}{l}\text { Longliner with freezing } \\
\text { facility }\end{array}$ & 14 & 220.6 & 56.2 & 13 & 388.1 & 79.6 & 40.40 & $\leq 0.001$ \\
\hline All ships & 153 & 161.9 & 60.4 & 128 & 377.1 & 119.2 & 381.90 & $\leq 0.001$ \\
\hline \multicolumn{9}{|c|}{ Time difference between minutes in bed, vs minutes asleep } \\
\hline Netting vessels & 31 & 125.9 & 52.3 & 30 & 70.1 & 29.8 & 25.95 & $\leq 0.001$ \\
\hline Longliners & 89 & 157.2 & 73.8 & 66 & 94.6 & 93.2 & 22.27 & $\leq 0.001$ \\
\hline Trawlers & 19 & 139.5 & 71.7 & 19 & 74.0 & 34.9 & 12.84 & $\leq 0.001$ \\
\hline $\begin{array}{l}\text { Longliner with freezing } \\
\text { facility }\end{array}$ & 14 & 125.7 & 31.3 & 13 & 89.1 & 44.8 & 6.16 & $<0.05$ \\
\hline All ships & 153 & 146.3 & 68.1 & 128 & 85.3 & 71.7 & 53.46 & $\leq 0.001$ \\
\hline \multicolumn{9}{|l|}{ Sleep efficiency (\%) } \\
\hline Netting vessels & 31 & 68.7 & 20.0 & 30 & 84.7 & 8.2 & 134.96 & $\leq 0.001$ \\
\hline Longliners & 89 & 62.8 & 23.3 & 66 & 82.6 & 10.6 & 378.97 & $\leq 0.001$ \\
\hline Trawlers & 19 & 67.1 & 23.8 & 19 & 84.6 & 7.9 & 79.36 & $\leq 0.001$ \\
\hline $\begin{array}{l}\text { Longliner with freezing } \\
\text { facility }\end{array}$ & 14 & 71.7 & 15.8 & 13 & 81.9 & 9.1 & 41.19 & $\leq 0.001$ \\
\hline
\end{tabular}


Table 3 (Continued).

\begin{tabular}{|c|c|c|c|c|c|c|c|c|}
\hline \multirow[t]{2}{*}{ Measures } & \multirow[b]{2}{*}{$\mathbf{N}$} & \multicolumn{2}{|c|}{ Sea } & \multirow[b]{2}{*}{$\mathbf{N}$} & \multicolumn{2}{|c|}{ Land } & \multirow[b]{2}{*}{$\mathbf{F}$} & \multirow[b]{2}{*}{ p - value } \\
\hline & & Mean & \pm SD & & Mean & $\pm S D$ & & \\
\hline All ships & 153 & 65.4 & 22.0 & 128 & 83.3 & 9.6 & 676.02 & $\leq 0.001$ \\
\hline \multicolumn{9}{|c|}{ Sleep fragmentation Index } \\
\hline Netting vessels & 31 & 72.0 & 30.6 & 30 & 31.1 & 15.9 & 330.69 & $\leq 0.001$ \\
\hline Longliners & 89 & 77.4 & 34.0 & 66 & 35.2 & 18.1 & 793.95 & $\leq 0.001$ \\
\hline Trawlers & 19 & 72.2 & 34.9 & 19 & 29.5 & 12.9 & 214.66 & $\leq 0.001$ \\
\hline $\begin{array}{l}\text { Longliner with freezing } \\
\text { facility }\end{array}$ & 14 & 59.0 & 27.9 & 13 & 37.3 & 16.4 & 59.83 & $\leq 0.001$ \\
\hline All ships & 153 & 72.6 & 33.4 & 128 & 33.6 & 16.8 & 1355.69 & $\leq 0.001$ \\
\hline \multicolumn{9}{|l|}{ Number of awakenings } \\
\hline Netting vessels & 31 & 17.3 & 10.1 & 30 & 21.4 & 10.7 & 15.23 & $\leq 0.001$ \\
\hline Longliners & 89 & 11.7 & 7.0 & 66 & 20.8 & 10.5 & 577.29 & $\leq 0.001$ \\
\hline Trawlers & 19 & 8.7 & 6.4 & 19 & 19.2 & 9.3 & 152.35 & $\leq 0.001$ \\
\hline $\begin{array}{l}\text { Longliner with freezing } \\
\text { facility }\end{array}$ & 14 & 16.7 & 7.7 & 13 & 22.3 & 10.4 & 43.12 & $\leq 0.001$ \\
\hline All ships & 153 & 13.0 & 7.7 & 128 & 20.9 & 10.4 & 682.40 & $\leq 0.001$ \\
\hline \multicolumn{9}{|c|}{ Wake After Sleep Onset (WASO) } \\
\hline Netting vessels & 31 & 99.6 & 85.8 & 30 & 64.0 & 40.3 & 33.72 & $\leq 0.001$ \\
\hline Longliners & 89 & 77.7 & 65.5 & 66 & 71.5 & 48.3 & 4.22 & $<0.05$ \\
\hline Trawlers & 19 & 51.9 & 48.5 & 19 & 65.5 & 42.0 & 7.61 & $\leq 0.01$ \\
\hline $\begin{array}{l}\text { Longliner with freezing } \\
\text { facility }\end{array}$ & 14 & 78.2 & 54.3 & 13 & 81.2 & 53.9 & 0.29 & 0.591 \\
\hline All ships & 153 & 77.3 & 64.0 & 128 & 69.7 & 46.4 & 13.19 & $\leq 0.001$ \\
\hline \multicolumn{9}{|l|}{ Sleep Latency } \\
\hline Netting vessels & 31 & 9.2 & 19.5 & 30 & 1.8 & 3.2 & 37.15 & $\leq 0.001$ \\
\hline Longliners & 89 & 8.9 & 16.9 & 66 & 1.6 & 2.5 & 105.29 & $\leq 0.001$ \\
\hline Trawlers & 19 & 7.6 & 12.9 & 19 & 1.7 & 2.1 & 33.72 & $\leq 0.001$ \\
\hline $\begin{array}{l}\text { Longliner with freezing } \\
\text { facility }\end{array}$ & 14 & 4.5 & 8.7 & 13 & 2.0 & 3.5 & 8.40 & $\leq 0.01$ \\
\hline All ships & 153 & 7.8 & 15.5 & 128 & 1.7 & 2.8 & $17 \mid .87$ & $\leq 0.001$ \\
\hline
\end{tabular}

Notes: Efficiency - number of sleep minutes divided by the total number of minutes the subject was in bed (ie, the difference between the In-Bed and Out-Bed-time). Sleep fragmentation Index - refers to the proportion of arousals (restlessness) during sleep (Gellman \& Turner, 2020). Movement index - proportion of movement during sleep average awakening length - refers to the average length, in minutes, of all awakening episodes during sleep. Wake After Sleep Onset (WASO) refers to periods of wakefulness occurring after defined sleep onset. This parameter measures wakefulness, excluding the wakefulness occurring before sleep onset. Number of awakenings refers to how many periods of awakenings are recorded after defined sleep onset. 
Table 4 Percentage of All Fishers' Ratings on the Karolinska Sleepiness Scale (KSS) and the Physical Tiredness Scale $\geq 7$ Against Three Levels (Low, Middle, and High) Pitch (Ship Movement Fore to Aft) and Roll (Ship Movement Side to Side)

\begin{tabular}{|l|l|l|l|l|l|l|}
\hline & & Pitch & & & Roll & \\
\hline Variables in Degrees & Low & Middle & High & Low & Middle & High \\
& $0.1-1.62$ & $1.66-2.28$ & $2.33-13.68$ & $0.5-3.49$ & $3.52-4.27$ & $4.29-11.8 \mathrm{I}$ \\
Mean & $\mathrm{M}=1.30$ & $1.66-2.28$ & $\mathrm{M}=1.96$ & $\mathrm{M}=4.46$ & $\mathrm{M}=3.9 \mathrm{I}$ & $\mathrm{M}=5.17$ \\
$\mathrm{SD}$ & \pm 0.29 & \pm 0.17 & \pm 2.64 & \pm 0.68 & \pm 0.24 & \pm 1.27 \\
All fleet scores of & $\mathrm{I} .15 \%$ & $13.37 \%$ & $19.15 \%$ & $18.7 \%$ & $12.91 \%$ & $15.52 \%$ \\
KSS $\geq 7$ & $\mathrm{~N}=297$ & $\mathrm{~N}=272$ & $\mathrm{~N}=395$ & $\mathrm{~N}=384$ & $\mathrm{~N}=259$ & $\mathrm{~N}=321$ \\
All fleet scores of & $8.71 \%$ & $7.88 \%$ & $16.31 \%$ & $14.33 \%$ & $7.97 \%$ & $9.43 \%$ \\
Physical tiredness $\geq 7$ & $\mathrm{~N}=163$ & $\mathrm{~N}=154$ & $\mathrm{~N}=250$ & $\mathrm{~N}=252$ & $\mathrm{~N}=133$ & $\mathrm{~N}=182$ \\
\hline
\end{tabular}

\section{Discussion}

For this study, objective and subjective data regarding sleep and sleepiness were collected from four types of Faroese fishing vessels representing four different shift work systems to obtain a greater understanding of how sleep, shift work, and fatigue influences the fishers' mental state while working at sea, together with certain environmental factors. Fishers have long and/or fragmented working days (9-18 hours a day), and most often disturbed sleep, in addition to a harsh working environment. All these factors are usually associated with increased fatigue. ${ }^{21}$

The main finding is that sleep was significantly worse at sea than on land. Several of the actigraphy variables support this. Split sleep was more common at sea than on land, and although there is significant variation between the vessel groups at sea, these intergroup differences are not seen on land. These findings are in support of the expectation that the conditions at sea are the causal factor. Furthermore, they are also in line with the previous findings showing that split sleep occurs more frequently at sea, and that sleep is less restorative at sea. ${ }^{22,23}$

In addition to having actigraphy confirming that the sleep periods are much shorter at sea, the study also confirms that the overall sleep per day is significantly shorter for all vessel types. The longliner with freezing facilities was the vessel group where the fishers get the most sleep per day; 5 hours and 33 minutes per 24-hours, usually divided into 1.5 sleep periods per day, 8 hours on/ 8 hours off. This is one hour more than the average of all the vessel groups, although the longliners without freezing facilities have the same ratio between sleep and work but work a different shift system; 6 hours on/ 6 hours off. The netting vessels worked for about 16 hours in a row and then had a rest period while work was stopped for 8 hours. The trawler crews worked three to four work periods per 24 hours, with shorter periods for sleep in between. This is far below what is suggested to be sufficient for recuperation. ${ }^{24}$

Several studies have pointed to the negative effects of split sleep when compared to individuals having one major sleep per day. Smith et $\mathrm{al}^{25}$ point out that working more than $2 \times 6$ hours per day should be avoided since this may cause increased levels of sleepiness. Fischer et $\mathrm{al}^{26}$ identified that the risk of injuries has been found to increase substantially when work exceeds nine consecutive hours and nearly triples after twelve hours. The much higher prevalence of severe sleepiness among the netting vessel and trawler crews confirms this finding.

Concerning split sleep, the longest mean continuous sleep period of the four vessel groups, as evidenced by actigraphy, is 4 hours and 41 minutes. The average sleep length of all the fishers altogether is 2 hours 42 minutes, with trawler crews getting just under 2 hours per sleep. Hence, the current results further confirm that insufficient resting periods (even if frequent), long consecutive work periods, and split sleep are major problems on-board these fishing vessels, with potentially severe negative effects on successful recuperation while on board.

Sleep efficiency was also significantly lower at sea than on land, irrespective of vessel type. The trend observed showed that fishers with the longest sleep periods at sea also had the highest sleep efficiency. In absolute terms, very low sleep efficiency percentages were observed for all vessels while on-board, mean $=65.4 \%$, ranging from $62.8 \%-71.7 \%$, when compared to the seafarers on the Seafarer's Fatigue Program ${ }^{25}$ and those from the Royal Norwegian Navy ${ }^{27}$ who had a mean sleep efficiency of $88.6 \%$ and $86.5 \%$ respectively. The large difference seen here between the current study 
and the other two mentioned might be caused, at least in part, by vessel size, since fishing vessels are often smaller than vessels in the merchant fleet, which also often have better stabilisation equipment, and consequently, fishers are expected to be more influenced by the weather.

In addition to split sleep, small amounts of rest, low sleep efficiency, and short sleep periods being rather predominant, a ship's movement further adds to a potentially highly insufficient recuperation period during the crew's time-off while on board. Among all vessel groups, apart from longliners with freezing facilities, highly significant differences are seen in the fishers' sleep fragmentation index at sea versus on land, showing that at sea, fishers sleep more restlessly with significantly more arousals during sleep, than what they do on land. It is likely that the higher proportion of arousals during sleep, together with an observed increased movement index at sea versus at land, might be due to vessel movement. Omlin et $\mathrm{a}^{28}$ suggest that minor, but regular, ship movement may positively affect sleep qualityrelated parameters. However, for the current study, it was found that ship-movements often were far beyond minor, and moreover quite irregular, since they were much dependent on changing weather conditions. The actigraphy measures also revealed that it took fishers much longer to fall asleep at sea than on land. The sleep latency was significantly longer at sea for all vessel groups. Additionally, it was mostly the working hours that determined the sleep hours, not the fishers' internal biological clocks. Again, this underpins the suboptimal environmental conditions for sleep on board. The short sleeps and low sleep efficiency were also depicted in the KSS ratings. These ratings were higher at the end of the trip than at the beginning. In addition, significant differences were seen as a function of day, with higher sleepiness ratings during the circadian nadir. Significant differences were also seen between the vessel groups, which clearly reflected the variation in sleep patterns, showing that the netting vessels had the largest difference in sleep lengths between land and sea, and reported the highest prevalence of severe sleepiness ratings (KSS $\geq 7$ ). In contrast, longliners with freezing facilities, the vessels with the lowest difference between length of sleep periods at sea and on land, also had the lowest frequency of KSS scores $\geq 7$. It therefore seems plausible that timing the sleep under conditions of no wake-up demand could serve as a good indication of an individual's natural sleep need. The fishers of the longliners with freezing facilities (working an 8-hour shift rotation) experienced the least severe sleepiness. Lastly, the reduced sleep at sea compared to on land and the increase in subjective reports of sleepiness (KSS scores) was reflected in cognitive decline, with an increase in the number of major lapses on the SRT test at the end of the trip. This is in line with the existing literature on psychomotor vigilance tasks (PVT) and fatigue, based on chronic partial sleep deprivation, that shows clear evidence of performance impairment. ${ }^{29-31}$ Furthermore, to draw a parallel, van Dongen et $\mathrm{al}^{30}$ found that a group with a 14-days chronic sleep restriction condition, reached the same level of lapses as a three-day total sleep-deprived population, and being chronically sleep-deprived is a quite accurate description of the fishers in this study.

In brief, both internal and external factors contribute to poor sleep at sea compared to sleep on land, reflected by all the sleep parameters discussed above. Ship movement and noise seemed to play a part, being correlated to the fishers' sleep efficiency, sleepiness levels and physical tiredness levels. Regarding ship movement, a clear U-shaped trend was seen. The trend could suggest that as the work is usually monotonous, a quantitative mental underload also becomes an additional risk factor. This means that "too little" ship movement is more likely to put the fishers into a state of drowsiness, while a little more ship movement forces the fishers to stay alert, confirming the findings in earlier studies. ${ }^{32,33}$ However, when the ship movement increases further, the fishers likely need to put too much energy into staying on their feet, as found by Breidahl et $\mathrm{al}^{34}$, as well as being required to continually lookout for dangers that might occur because of the ship's movement. This causes elevated levels of physical tiredness and sleepiness and increases the risk of fatigue among workers. ${ }^{35}$

To our knowledge, no study has previously provided objective measures of noise on fishing vessels operating at sea, although three field studies with objective measurements of noise and sleep were identified on other types of vessels. ${ }^{25,27,36}$ Our results on sleep disturbance due to noise went in diverging directions. It seems that noise during the working day increases sleep efficiency, while noise during the resting hours has a negative effect on sleep efficiency. Since noise exposure during work was positively correlated with KSS and physical tiredness, it could suggest that noise pollution while at work might make the fishers more tired, and thereby possibly increase sleepiness and fatigue which may, in turn, elevate the sleep efficiency. On the contrary, if there is a high level of noise $(\mathrm{dB}(\mathrm{A}))$ in the resting area, it 
will impair sleep efficiency. Thus, a noisy work environment is not desirable, although being more tired might heighten sleep efficiency. ${ }^{37}$

Although noise exposure $(\mathrm{dB}(\mathrm{A}))$ at work and in the fishers' time off explained some of the variances in terms of the fishers' sleep efficiency, sleepiness, and tiredness ratings, the relationship proved to be lower than expected, considering the higher noise exposure compared to the previous studies using objective measures of decibel level and sleep ${ }^{27,36}$ and the findings in a survey that over half of the seafarers rated noise as a disturbing factor for sleep. ${ }^{20}$ The main explanation could be the little variation in the noise profiles. As variation is a prerequisite for identifying statistical differences in effects estimates, the minimal variation could explain why significant results are not obtained. However, the high mean level of noise exposure evidences a health problem in this population. This could suggest that when tired, the fishers adapt to high noise exposure, and with an overall mean of over 16 years in this occupation, the constant noise exposure might also have caused a hearing impairment in some fishers. Nevertheless, this cannot be confirmed in the current study since the fishers' hearing was not tested.

We can conclude that the periods awake during sleep are significantly longer at sea than on land which may partly be caused by the fishers being forced to sleep at unfavourable hours of the day, which is in line with the findings of, for instance, Gander et al, ${ }^{23}$ who found a clear preference for night-time sleep.

Cognitive decline was found, with the number of major lapses being higher at the end of the trip, but with no significant difference between the median reaction times.

It has been concluded that lapses are an easily recognised occurrence of sleep-deprived individuals and are therefore an excellent measure of fatigue. ${ }^{38}$ Our findings are coherent with this and confirm this conclusion.

\section{Strengths and Limitations}

A strength of the study is that it was conducted in the fishers' typical working environment where the researcher was at sea while collecting the data. However, it might also have caused a phenomenon that is typically referred to as the Hawthorne effect, where a researcher's presence on board might have altered the fishers' normal behaviour. Furthermore, the participation rate was high, with most of the vessels in each vessel group participating, making our sample representative for crews working on similar vessels with similar shifts, ie 6-on/6-off, 8-on/8-off, 16-on/8-off, and for the small trawler vessels, a usual working period of several 2-hour stretches a day. This is, to our knowledge, the first large-sample field study with objective measures of sleep ( $\mathrm{n}=4133$ sleep periods) and noise (collected by decibel measure, on-board 16 ships, 18 trips, with 6-10 hours measured in each workstation). Being a naturalistic field study, it was not possible to control the start and end time of each trip. The researcher had to adapt fully to the captain's working schedule for the vessels. Furthermore, it was evident that the energy level of the crew was higher when entering the ship than at the end, with the crew sharing news between them, telling good stories and talking more than at the end of the trip. This might have caused a higher level of distraction during the testing sessions at the beginning compared to the end of the trip, causing less standardised circumstances. Also, at the beginning of the trip, a whole crew would be conducting the tests simultaneously, while at the end, when fishers worked in shifts, only half of the crew would be tested at a time. For this reason, distraction levels may be higher during the first testing sequence compared to the last. If this were the case, then one can speculate that if this group distraction caused the fishers to perform at a suboptimal level at the beginning, we could not, therefore, observe the expected decline at the end.

Regarding the sleep diaries, the on-board researcher tried to give reminders. Still, with self-reports, it could not be avoided that some left longer time than the two hours between their registrations. Moreover, there is a risk that some might have filled in the sleep and sleepiness registrations just before submitting. A few also reported that they had lost the paper version, and even though some asked for a new one right away, some data was lost. However, despite some registrations being omitted and that there sometimes was more than two hours between registrations, overall, the fishers were quite good at registering.

Due to technical problems and corrupt files, some actigraph files were lost. However, most of the time, the battery of the watch went empty before the end of the trip. Here the procedure was, that the fishers told the on-board researcher when only $10 \%$ was left, and then a new watch was prepared for the fisher and swopped when the battery went empty or was down to $1 \%$. This way, even though sleep periods were lost, sleep measures from the vast majority of fishers could 
be obtained. Furthermore, it very rarely happened that some fisher had taken the watch off during sleep. One fisher stopped wearing the watch during half of the trip because he said that the watch disturbed his sleep.

Not using personal dosimeters to measure noise gives less accurate measures per person than when measuring working stations and calculating the individual profiles. For future studies, one should aim to use personally worn dosimeters instead and time-match the decibel profiles with the actigraphy registrations.

\section{Conclusion}

The organisation of the work seems to play the most crucial role in the fishers' sleep and sleepiness levels at sea. Overall, it appears that fishers on the freezing longliners get the longest periods of sleep, have the highest sleep efficiency, the lowest sleep latency, and are the least tired or sleepy during the day. The study suggests that multiple split sleeps reduced sleep efficiency, as seen with the trawler crew. The study also confirms that a high work-to-rest ratio is more likely to cause sleepiness and fatigue problems. Ship movement and noise also played a role in influencing the fishers' sleep efficiency and sleepiness.

Future studies should aim at testing the same crew repeatedly for a few trips, using the same instruments, but with the crew working different systems each trip, to understand the role of the shift system and which factors protect the workers from reaching high levels of fatigue. Preferably, one should test the crew of a longliner with freezing facilities to see if one can answer why they were the least fatigued, despite working an average of 12 hours a day for 39 days. The most interesting finding regarding ship movement was the curved trend showing that some ship movement had a preventive effect on fatigue, probably through the need for increased alertness compared to minimal ship-movement, that increased sleepiness. However, a high increase in ship movement still took its toll on the fishers and resulted in higher sleepiness scores than with a very quiet sea. The fact that a very calm sea increased the sleepiness ratings may be a manifestation of accumulated sleep debt combined with a lower need of attention. This effect might be further amplified with the work tasks often being monotonous. Therefore, we observe fatigue manifests itself under quiet conditions.

\section{Acknowledgments}

The authors would like to thank Rógvi Lydersen for his invaluable help with preparing and analysing the noise and ship movement data, Jógvan á Høvdanum for involvement in data collection, Michael Victor Christensen, cand.mag. Computer software professionals for advice on how to prepare the ship movement data for analysis and Maria Skaalum Petersen and Turid Hammer for reading through the work and giving valuable advice. Furthermore, we want to thank Fiskeriets Arbejdsmiljøråd, with Flemming Nygaard Christensen, for letting us borrow the gyroscope for conducting the ship movement loggings for the analyses, and Lis H. Magnussen, at the Faroese Fisheries Inspection (vorn.fo), for co-operation in getting in contact with the captains when ships arrived in harbour and made it possible to make arrangements for getting onboard the vessels. Last, but not least, we would like to show our gratitude to the fishers for participating in the study.

\section{Funding}

This work was supported by the Faroese Research Council (grant \# 0340); the Fisheries Research Fund of the Faroe Islands; the Faroese Agricultural Foundation; the Faroese Union of Shipmasters and Navigators; The Faroese Marine Engineering Union; The Faroese fishermen Union; The Workers Union of Kollafjørður; and the Workers Union Hoeddin.

\section{Disclosure}

The authors report no conflict of interest.

\section{References}

1. Goossens RHM, Murata A, editors. AHFE 2019. AISC 970; 2020: 379-392. doi:10.1007/978-3-030-20145-6_38

2. McGuinness E, Aasjord HL, Utne IB, Holmen IM. Fatalities in the Norwegian fishing fleet 1990-2011. Saf Sci. 2013;57:335-351. doi:10.1016/j. ssci.2013.03.009

3. Christiansen JM, Hovmand SR. Prevention of Accidents at Work in Nordic Fisheries - What Has Worked? Nordic Council of Ministers; 2017. doi:10.6027/TN2017-509 
4. Jensen OCC, Petursdottir G, Holmen IM, Abrahamsen A, Lincoln JA. A review of fatal accident incidence rate trends in fishing. Int Marit Health. 2014;65(2):47-52. doi:10.5603/IMH.2014.0011

5. Thorvaldsen T, Kaustell KO, Mattila TEA, et al. What works? Results of a Nordic survey on fishers' perceptions of safety measures. Mar Policy. 2018;95:95-101. doi:10.1016/j.marpol.2018.06.022

6. Wadsworth EJK, Allen PH, McNamara RL, Smith AP. Fatigue and health in a seafaring population. Occup Med. 2008;58(3):198-204. doi:10.1093/ occmed/kqn008

7. Raby M, Lee JD. Fatigue and Workload in the maritime industry. In: Stress, Workload, and Fatigue. P.A. Ha. Mahwah, New Jersey: Lawrence Erlbaum associates; 2000:566-578.

8. Jepsen JR, Zhao Z, Pekcan C, Barnett M, Leeuwen W. Risk factors for fatigue in shipping, the consequences for seafarers' health and options for preventive intervention. Maritime Psychol. 2017:127-150. doi:10.1007/978-3-319-45430-6

9. Allen P, Wadsworth E, Smith A. Seafarers' fatigue: a review of the recent literature. Int Marit Health. 2008;59(1-4):81-92.

10. Høvdanum A, Jensen OC, Petursdóttir G, Holmen IM. A review of fatigue in fishermen: a complicated and underprioritised area of research. Int Marit Health. 2014;65(3):166-172. doi:10.5603/IMH.2014.0031

11. Wagstaff AS, Lie JA. Shift and night work and long working hours - a systematic review of safety implications. Scand J Work Env Heal. 2011;37 (3):173-185. doi:10.5271/sjweh.3146

12. Van leeuwen WMA, Pekcan C, Barnett M, Kecklund G. Mathematical modelling of sleep and sleepiness under various watch keeping schedules in the maritime industry. Mar Policy. 2020;130. doi:10.1016/j.marpol.2020.104277

13. Parkes KR. Work environment, overtime and sleep among offshore personnel. Accid Anal Prev. 2015;99. doi:10.1016/j.aap.2015.11.022

14. Parkes KR. Age, smoking, and negative affectivity as predictors of sleep patterns among shiftworkers in two environments. $J$ Occup Health Psychol. 2002;7(2):156-173. doi:10.1037/1076-8998.7.2.156

15. Dembe AE, Erickson JB, Delbos RG, Banks SM. The impact of overtime and long work hours on occupational injuries and illnesses: new evidence from the United States. Occup Environ Med. 2005;62(9):588-597. doi:10.1136/oem.2004.016667

16. Ohayon MM, Smolensky MH, Roth T. Consequences of shiftworking on sleep duration, sleepiness, and sleep attacks. Chronobiol Int. $2010 ; 27$ (3):575-589. doi:10.3109/07420521003749956

17. Åkerstedt T. Work hours, sleepiness and the underlying mechanisms. J Sleep Res. 1995;4. doi:10.1111/j.1365-2869.1995.tb00221.x

18. Åkerstedt T. Shift work. Encyclopedia Sleep. 2013. doi:10.1016/B978-0-12-378610-4.00040-1

19. Saremi M, Rohmer O, Bonnefond A, Muzet A, Tassi P, Burgmeier A. Combined effects of noise and shift work on fatigue as a function of age. Int J Occup Saf Ergon. 2008;14(4):387-394. doi:10.1080/10803548.2008.11076779

20. Hansen JH, Holmen IM. Sleep disturbances among offshore fleet workers: a questionnaire-based survey. Int Marit Health. 2011;62(2):123-130.

21. Rezaee S, Brooks MR, Pelot R. Review of fishing safety policies in Canada with respect to extreme environmental conditions and climate change effects. WMU J Marit Aff. 2016;1-17. doi:10.1007/s13437-016-0110-z

22. Gander P. A review of the fatigue management of the maritime sector. Massey University Sleep/Wake Research Centre; $2005: 2005$.

23. Gander P, van den Berg M, Signal L. Sleep and sleepiness of fishermen on rotating schedules. Chronobiol Int. 2008;25(2-3):389-398. doi:10.1080/ 07420520802106728

24. Strauch B. Investigating fatigue in marine accident investigations. Procedia Manuf. 2015;3:3115-3122. doi:10.1016/j.promfg.2015.07.859

25. Smith A, Allen P, Wadsworth E. Seafarer fatigue: the Cardiff research programme; 2006.

26. Fischer D, Lombardi DA, Folkard S, Willetts J, Christiani DC. Updating the "Risk Index": a systematic review and meta-analysis of occupational injuries and work schedule characteristics. Chronobiol Int. 2017;34(10):1423-1438. doi:10.1080/07420528.2017.1367305

27. Sunde E, Bratveit M, Pallesen S, Moen B. Noise and sleep on board vessels in the Royal Norwegian Navy. Noise Heal. 2016;18(81):85-92. doi:10.4103/1463-1741.178481

28. Omlin X, Crivelli F, Näf M, et al. The effect of a slowly rocking bed on sleep. Sci Rep. 2018;8(1):1-10. doi:10.1038/s41598-018-19880-3

29. Dinges DF, Pack F, Williams K, et al. Cumulative sleepiness, mood disturbance, and psychomotor vigilance performance decrements during a week of sleep restricted to 4-5 hours per night. Sleep. 1997;20(4):267-277. doi:10.1093/sleep/20.4.267

30. Van Dongen HP, Maislin G, Mullington JM, Dinges DF, The cumulative cost of additional wakefulness: dose-response effects on neurobehavioral functions and sleep physiology from chronic sleep restriction and total sleep deprivation. Sleep. 2003;26(2):117-126. doi:10.1093/sleep/26.2.117

31. Tilley AJ, Wilkinson RT. The effects of a restricted sleep regime on the composition of sleep and on performance. Psychophysiology. $1984 ; 21$ (4):406-412. doi:10.1111/j.1469-8986.1984.tb00217.x

32. Weng J, Yang D, Chai T, Fu S. Investigation of occurrence likelihood of human errors in shipping operations. Ocean Eng. 2019;182:28-37. doi:10.1016/j.oceaneng.2019.04.083

33. Williamson A, Lombardi DA, Folkard S, Stutts J, Courtney TK, Connor JL. The link between fatigue and safety. Accid Anal Prev. 2011;43 (2):498-515. doi:10.1016/j.aap.2009.11.011

34. Breidahl T, Christensen M, Jepsen JR, Johansen JP, Omland Ø. The influence of ship movements on the energy expenditure of fishermen. A study during a North Sea voyage in calm weather. Int Marit Health. 2013;64(3):114-120.

35. Duncan CA, MacKinnon SN, Marais JF, Basset FA. Energy cost associated with moving platforms. PeerJ. 2018;2018(8):1-16. doi:10.7717/ peerj.5439

36. Smith A, Lane T, Bloor M, Allen P, Burke A, Ellis N. Fatigue offshore: Phase 2 the short sea and coastal shipping industry. Cabe M, ed. In: $P$. T. 1st ed; 2003.

37. Shrivastava D, Jung S, Saadat M, Sirohi R, Crewson K. How to interpret the results of a sleep study. J Community Hosp Intern Med Perspect. 2014;4(5):24983. doi:10.3402/jchimp.v4.24983

38. Doran SM, Van Dongen HPA, Dinges DF. Sustained attention performance during sleep deprivation: evidence of State Instability. Arch Ital Biol. 2001;139(3):253-267. 


\section{Publish your work in this journal}

Nature and Science of Sleep is an international, peer-reviewed, open access journal covering all aspects of sleep science and sleep medicine, including the neurophysiology and functions of sleep, the genetics of sleep, sleep and society, biological rhythms, dreaming, sleep disorders and therapy, and strategies to optimize healthy sleep. The manuscript management system is completely online and includes a very quick and fair peer-review system, which is all easy to use. Visit http://www.dovepress.com/testimonials.php to read real quotes from published authors.

Submit your manuscript here: https://www.dovepress.com/nature-and-science-of-sleep-journal 